\title{
Spectral Fatigue Life for Simple Notched Component
}

Adam Kalavský, Róbert Huňady, Pavol Lengvarsky

Faculty of Applied Mechanics and Mechanical Engineering, Technical University of Košice. Letná 9, 04200 Košice.Slovak Republic. E-mail: adam.kalavsky@tuke.sk, robert.hunady@tuke.sk, pavol.lengvarsky@tuke.sk

The paper describes a procedure for calculating the lifetime in the frequency domain, which is supplemented by an experiment. The aim of the experiment was to find the required mechanical properties of the material to describe the behavior of the material during fatigue analysis. Experimental modal analysis was performed to estimate damping, which supported numerical calculation and refined results of numerical simulations. The authors made an estimate of fatigue curve (SN-curves) according to ČSN 42 0363 and ČSN ISO 12107 standards. Knowledge of material fatigue, statistics, modal analysis and signal processing were used in the experimental and numerical part.

Keywords: S-N curve, spectral fatigue, life prediction, Dirlik

\section{Introduction}

The most common cause of machine parts failure is fatigue of the material. This phenomenon occurs as a result of cyclic stressing of the machine part caused by frequent changes in load. In technical practice, we encounter a large number of highly cyclically stressed mechanical components. As the field of uniaxial highcycle fatigue is relatively well known today, current authors focus more on more complex loading systems or. principles of fatigue life estimation. There are various studies that deal with high-cyclic fatigue from different perspectives, such as fatigue life under multiaxial loading [3],[6],[15],[18],[19] or under different conditions, e.g. elevated temperature [1],[10],[11]. All these tasks can be solved numerically using two approaches - in the time domain and in the frequency domain. The time domain provides a more accurate estimate of fatigue life based on state-of-the-art knowledge, where we obtain a relatively good estimate of life by various linear as well as non-linear criteria. On the other hand, these time approaches are computationally time consuming. If we want to avoid lengthy calculations and save computing capacity, we are currently inclined to use the frequency domain. Many authors [2],[9],[13],[14],[16] have dealt with the principles of frequency life calculation, but it should be noted that this approach loses the accuracy of the calculations. This is due to the fact that the frequency histogram obtained by the Rainflow matrix in estimating the lifetime in the time domain is approximated in the frequency domain by a PDF function, which is obtained based on the parameters of the power spectral density (PSD) function.

\section{Theory backgroung}

Wöhler's "material" curves (Wöhler, 1860), in English often referred to as the S-N curve, shows fatigue life versus the stress amplitude of a smooth material specimen. It can be experimentally determined for different cycle asymmetries which are expressed by the cycle asymmetry factor

$$
R=\frac{\sigma_{\min }}{\sigma_{\max }} .
$$

The curves of most materials can be very well approximated by Basquin's law

$$
\sigma_{a}=\sigma_{f}^{\prime}\left(2 N_{f}\right)^{b}
$$

Where:

$\sigma_{f}^{\prime} \quad \ldots$ fatigue strength coefficient,

$b \quad \ldots$ exponent of fatigue strength,

$2 N_{f} \cdots$ represents the number of half-cycles to failture [20][21].

The most commonly used probability model for calculating fatigue life in the frequency domain is Dirlik model, which discribes a material behaviour at narrow-banding loadning as well as behaviour at widebanding loading. It is given by formula

$$
p\left(\sigma_{a}\right)_{\text {Dirlik }}=\frac{\frac{D_{1}}{Q} \cdot \mathrm{e}^{\frac{-Z_{i}}{Q}}+\frac{D_{2}}{R^{2}} \cdot \mathrm{e}^{\frac{-Z_{i}^{2}}{2 R^{2}}}+D_{3} \cdot Z_{i} \cdot \mathrm{e}^{\frac{-Z_{i}^{2}}{2}}}{2 \cdot \sqrt{m_{0}}} .
$$

Where:

$$
\begin{aligned}
& m_{0}, m_{1}, m_{2}, m_{4} \ldots \text { spectral moments, } \\
& D_{1}, D_{2}, D_{3}, R, Q \quad \ldots \text { coeficients, } \\
& Z_{i} \ldots \text { modified stress amplitude [7][12]. }
\end{aligned}
$$

Miner's rule of total damage was used to calculate the damage given by the sum of partial damages in form 


$$
D=\sum_{i=1}^{k} d_{i}=\sum_{i=1}^{k} \frac{n_{i}}{N_{i}}=1
$$

Where:

$D$... damage,

$d_{i} \quad \ldots$ partial damage,

$N_{i} \quad \cdots$ average number of cycles to failure at the i-th stress level,

$n_{i} \quad \ldots$ is the number of cycles accumulated at stress level [8].

\subsection{Estimation of material SN curves}

The SCHENCK PWS 0007 test apparatus was used to create material S-N curves. Fatigue tests were performed as cyclic bending tests on a fully reversed cycle $(\mathrm{R}=-1)$ on two types of specimens, specifically smooth (normalized) and notched specimens (Fig. 1). Specimens were made of one piece of aluminum sheet with a constant thickness of $4 \mathrm{~mm}$. The specimen's material was aluminum alloy Al5052 with H32 finish. The tests were carried out at the same temperatures and at $21^{\circ} \mathrm{C}$.

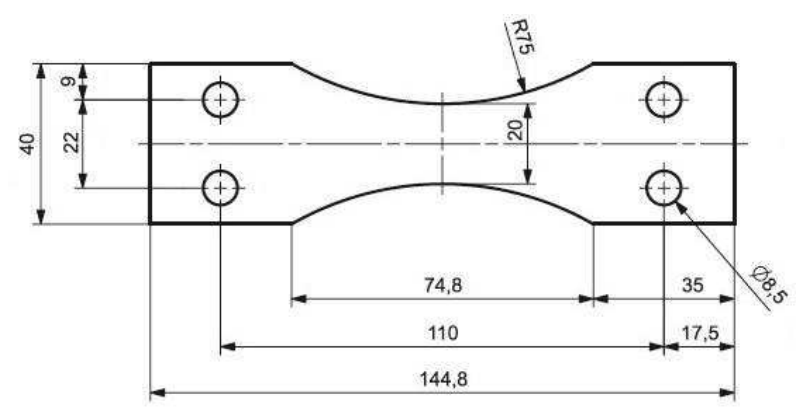

a)

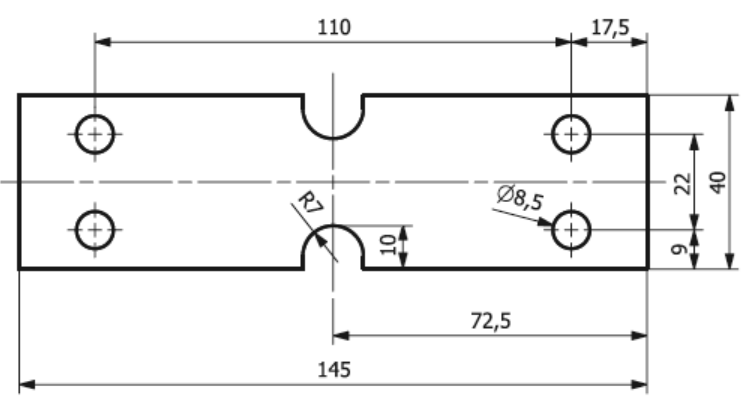

b)

Fig. 1 Types of specimen used to creating of material $s-n$ curves. (a) smooth (normalized) specimen for bending fatigue test,

(b) specimen with u-shape notch for bending fatigue test.

The S-N curve for a smooth, unnotched specimen was determined by statistical processing of the data obtained in the bending fatigue test. First specimen was loaded by bending moment which invokes the stress value started at $192.8 \mathrm{MPa}$ after failure. The number of cycles to failure was read and the value was filled in a table for statistical evaluation of the fatigue curve. The other measurements were continued in this way and the load was reduced by approx. $5 \mathrm{MPa}$ per one stress level.

A standard ČSN 420363 [4] describes the method of loading and evaluation of specimens, which are subjected to variable amplitude. This standard requires 8 specimens to describe a slop of fatigue curve. In ours measurments were used 20 specimens but some specimens had to be eliminated from testing group due to wrong measurement. To statistical proccesing was used the standard ČSN ISO 12107 [5], which offers three types of fatigue curve aproximation. The linear aproximation (2) describes by Basquin formula was choosen.

Where:

$$
\log N=a+b \sigma
$$

$$
a=\frac{1}{n} \sum_{i=1}^{n} \log N_{i}-b \frac{1}{n} \sum_{i=1}^{n} \sigma_{i},
$$

$$
b=\frac{\frac{1}{n} \sum_{i=1}^{n}\left(\log N_{i}\right) \sigma_{i}-\sum_{i=1}^{n} \sigma_{i} \sum_{i=1}^{n} \log N_{i}}{n \sum_{i=1}^{n} \sigma_{i}^{2}-\left(\sum_{i=1}^{n} \sigma_{i}\right)^{2}},
$$

The shape and results of the S-N curves for the notched and smooth specimen are shown in Fig. 2 and values necessary for numerical calculation are filled in Tab. .

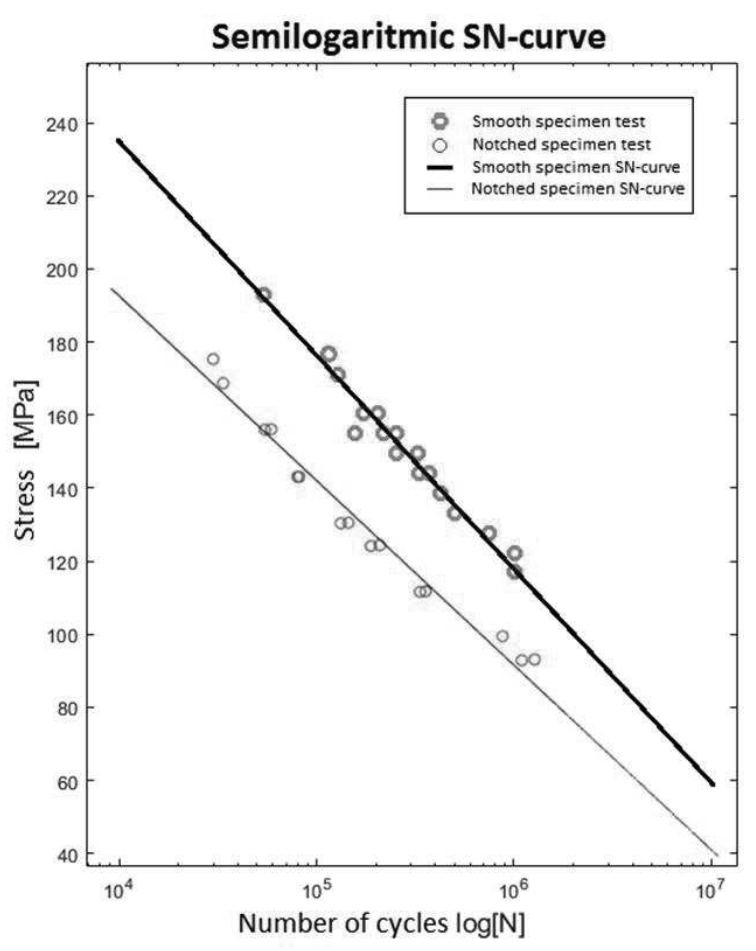

Fig. 2 SN-curves 
Tab. $1 \mathrm{~V}$ alues read from fatigue curve for smooth specmen

\begin{tabular}{|c|c|c|}
\hline $\begin{array}{c}\text { Number } \\
\text { of cycles }\end{array}$ & $\begin{array}{c}\text { Smooth speci- } \\
\text { men } \\
\text { (Stress }[\mathrm{MPa}] \text { ) }\end{array}$ & $\begin{array}{c}\text { Notched speci- } \\
\text { men } \\
\text { (Stress [MPa]) }\end{array}$ \\
\hline 10000 & 234.7 & 198.2 \\
\hline 50000 & 191.9 & 160.7 \\
\hline 100000 & 175.4 & 144.6 \\
\hline 250000 & 153.5 & 123.3 \\
\hline 500000 & 137.0 & 107.1 \\
\hline 1000000 & 117.9 & 91.0 \\
\hline 1500000 & 110.8 & 81.6 \\
\hline
\end{tabular}

The results clearly show that the notched specimen is weakened due to the notch. It could be seeing in Tab. 1, because a decrease in the fatigue life (number of cyclesto failure) is approximately about $20 \%$ for the notched specimen. Therefore, it is necessary to use the fatigue curve of notched specimen if we are working with notched construction or we should be use some correction coeficient.

\subsection{Fatigue test}

Ten test specimens (Fig. 3 (a)) were subjected to a random vibration fatigue test. Before starting the measurement, it was necessary to set the appropriate amplitude on the input excitation signal, which generated white noise in the range 25-800 cycles per second. Two uniaxial acceleration sensors were placed on the specimen (Fig. 3 (b)).

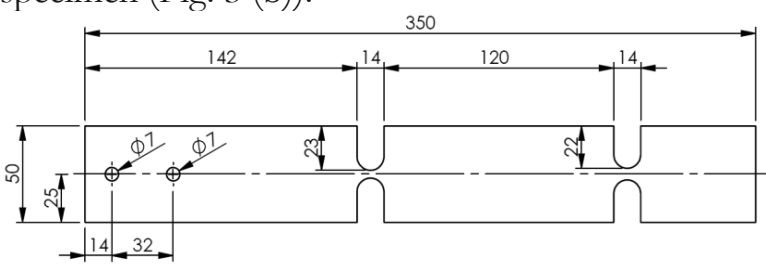

a)

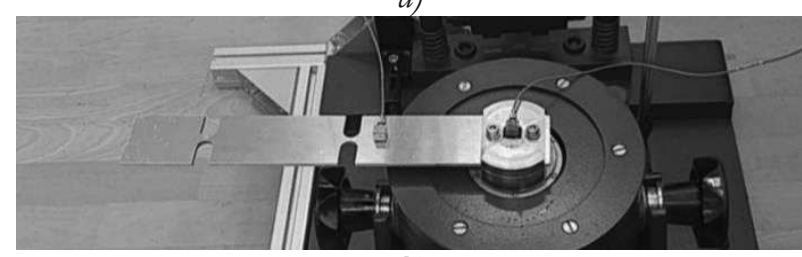

b)

Fig. 3 a) shape and dimensions of specimen, (b) measuring set prepared to experiment

All specimens were tested under the same conditions. The time to failure (Tab. 2) ranged from 815 to $1470 \mathrm{~s}$. The standard deviation at this interval was $175.9 \mathrm{~s}$. The average time to fatigue failure of the test specimens at the oscillation is $1095 \mathrm{~s}(18 \mathrm{~min}$ and 25 sec). The location of the failure (Fig. 6) was identical in all cases.

Tab. 2Time to specimens damage

\begin{tabular}{|c|c|c|c|c|c|}
\hline Serial num. & Spec. num. & Damage time & Serial num. & Spec. num. & Damage time \\
\hline 01 & 03 & $1040 \mathrm{~s}(17 \mathrm{~min} 20 \mathrm{~s})$ & 06 & 09 & $820 \mathrm{~s}(13 \mathrm{~min} 40 \mathrm{~s})$ \\
\hline 02 & 05 & $1445 \mathrm{~s}(24 \mathrm{~min} 05 \mathrm{~s})$ & 07 & 10 & $1132 \mathrm{~s}(18 \mathrm{~min} 52 \mathrm{~s})$ \\
\hline 03 & 06 & $1000 \mathrm{~s}(16 \mathrm{~min} 40 \mathrm{~s})$ & 08 & 11 & $1150 \mathrm{~s}(19 \mathrm{~min} 10 \mathrm{~s})$ \\
\hline 04 & 07 & $815 \mathrm{~s}(13 \mathrm{~min} 35 \mathrm{~s})$ & 09 & 12 & $1470 \mathrm{~s}(24 \mathrm{~min} 30 \mathrm{~s})$ \\
\hline 05 & 08 & $1022 \mathrm{~s}(17 \mathrm{~min} 02 \mathrm{~s})$ & 10 & 13 & $1058 \mathrm{~s}(17 \mathrm{~min} 38 \mathrm{~s})$ \\
\hline
\end{tabular}

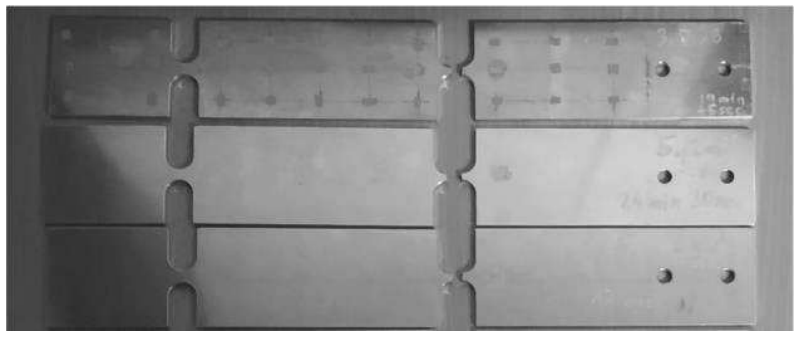

Fig. 4 Fatigue damage of specimens.

\subsection{Modal analysis}

Modal analysis (Fig. 5) was performed on fatigue test specimens to verify the natural frequencies and to determine damping. The damping ratios obtained experimentally were used in the simulation to refine the response of the numerical model. Experimental modal analysis was performed using PULSE system. The responses were measured by Polytec PDV-100 laser vibrometer and the structure was excited by Bruel \& Kjaer 8206 modal hammer. The selected modal parameters corresponding to bending shapes are shown in Tab. 3.

The numerical modal analysis was performed in program CAE Abaqus. The obtained eigenfrequencies are also shown in Tab. 3.

Differencies in values of eigenfrequencies were caused by ideal fixation of the specimen in numerical simulations. It may have a small negative effect for fatigue calculation.

Tab. 3 Eigenfrequencies and damping of the test specimen, corresponding to bending shapes.

\begin{tabular}{ccccc}
\hline Eigenmode & $\begin{array}{c}\text { Eigenfrequency } \\
\text { (FEM) [Hz] }\end{array}$ & $\begin{array}{c}\text { Damped eigenfrequency } \\
\text { (EMA) [Hz] }\end{array}$ & $\begin{array}{c}\text { Damping ra- } \\
\text { tio [\%] }\end{array}$ & $\begin{array}{c}\text { Mode comple- } \\
\text { xity }\end{array}$ \\
\hline 1. & 31.08 & 31.80 & 1.22684 & 0.01680 \\
3. & 217.65 & 191.68 & 0.45291 & 0.00278 \\
5. & 498.69 & 472.87 & 0.22234 & 0.00074 \\
8. & 1114.7 & 1081.90 & 0.09551 & 0.00378 \\
\hline
\end{tabular}




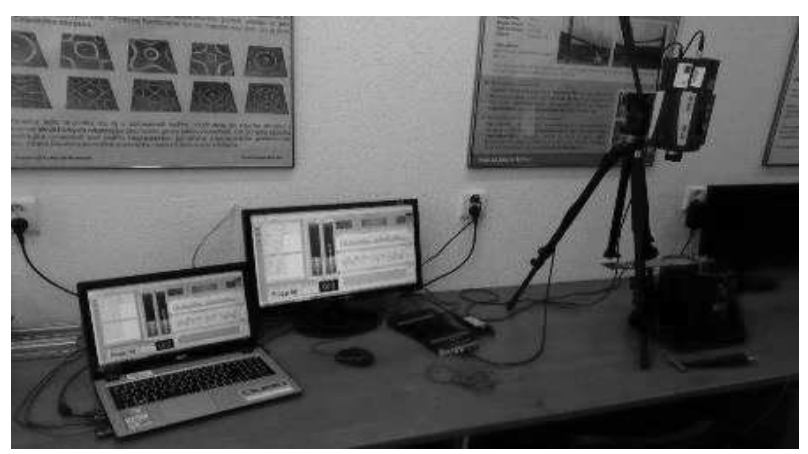

Fig. 5 EMA - measurement process.

\section{FEM-simulation}

Linear dynamic analysis was performed in CAE Abaqus. The model was excited by acceleration in one direction, which was applied perpendicular to the largest surface and the accelerometer location was at the same location as the acceleromater location in the experiment.

The lifetime calculation in frequency domain was performed in FE-SAFE, where the Dirlik method was chosen, which generally covers calculations of both narrowband and broadband signals. Modal stresses (Fig. 6 (a)) obtained in modal analysis, generalized phase angle shifts, obtained in frequency analysis using ABAQUS software were used as output data for fatigue life calculation. The S-N curve of the notched specimen was used in the calculation to give a more accurate estimate. The resulting field of damage in logarithmic values can be seen at (Fig. 6 (b)), showing that the most damaged place is consistent with the experiment.

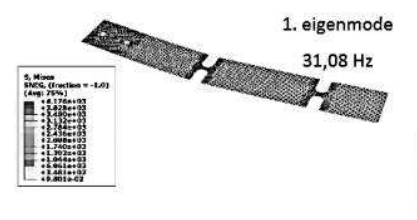

LOGufe-Repeats SNEG, $($ fraction $=-1.0$ )

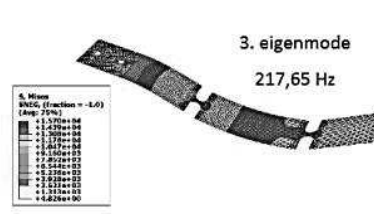

a)
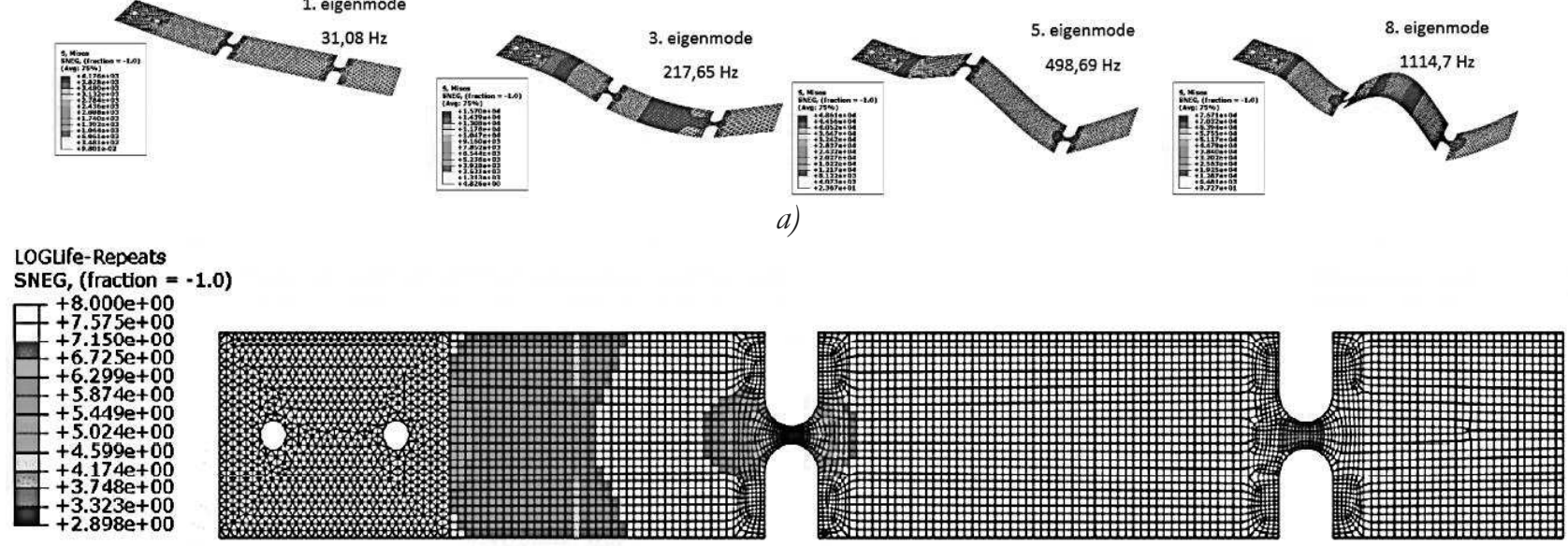

(b)

Fig. $\boldsymbol{\sigma}$ (a) First four bending eigenmodes. (b) Damage field of investigated specimen.

\section{Conclusion}

$2 \times 20$ specimens were subjected to bending tests to obtain fatigue characteristics. The obtained characteristics were used in the numerical calculation. 10 specimens were subjected to the fatigue life test of a notched beam under the dynamic loading. The average time to failure of the beam was determined by the experimental analysis at 1095 seconds. The numerical analysis of the fatigue life using the Dirlik method was 791 seconds and for the Tovo-Benasciutti method 796 seconds. In both cases, the S-N curve of the notched specimen was considered, due to more accuracy. The differences in the results can be attributed to the ideal rigid of the specimens in the FEM program, the approximation of the PSD signal, the damping of the individual eigenmodes, and the accuracy of the $\mathrm{S}-\mathrm{N}$ curves.

\section{Acknowledgement}

This research was supported by project VEGA 1/0355/18.

\section{References}

[1] BELAN, J. et al. (2018). The High-Temperature Loading Influence on Orthorhombic $\mathrm{Ni3Nb}$ DOa $\delta$ - Phase Formation and its Effect on Fatigue Lifetime in Alloy 718. Manufacturing Technology. 2018. Vol. 18, no. 6, pp. 875-882. doi: $\quad 10.21062 /$ ujep/194.2018/a/12132489/MT/18/6/875

[2] BENASCIUTTI, D., TOVO, R. (2005). Spectral methods for lifetime prediction under wide-band stationary random processes. Interantional Journal of Fatigue. Vol. 27, no. 8. 2005. pp. 867-877. doi:https://doi.org/10.1016/j. ijfatigue.2004.10.007

[3] BERNASCONI, A. et al. (2006). Multiaxial fatigue of a railway wheel steel under non-proportional loading. In International Journal of Fatigue. 2006. Vol. 28, no. 5, pp. 663-672.

[4] ČsN 420363. Metal fatigue tests. 1986. [Czech] 
[5] ČSN ISO 12107: Metal materials - Fatigue testing Statistical planning and data analysis. s.l. : Normservis s.r.o., 2013. [Czech]

[6] DELAHAY, T. - PALIN-LUC, T. (2006). Estimation of the fatigue strength distribution in high-cycle multiaxial fatigue taking into account the stress-strain gradient effect. In International Journal of Fatigue. 2006. Vol. 28, no. 5, pp. 474 484.

[7] KALAVSKÝ, A. (2017). Proposal of methodology for the computation of lifespan for stochastic loading including dynamic behaviour. Master thesis. Košice, 2017, pp. 75. [Slovak]

[8] MINER.M.A. (1945). Cumulative damage in fatigue. Journal of Applied Mechanics. Vol. 67, 1945, pp. 159-164

[9] MRŠNIK. M. et al. (2013). Frequency-domain methods for a vibration-fatigue-life estimationapplication to real data. International Journal of $\mathrm{Fa}$ tigue. Vol. 47. 2013. pp. 8-17. doi: https:// doi.org/10.1016/j.ijfatigue.2012.07.005

[10] NESLÁDEK, M. et al. (2019). Thermo-Mechanical Fatigue of a CrMo Steel Applicable to Steam Turbine Shafts. Procedia Structural Integrity. Vol. 19. 2019. pp. 231-237. doi: https://doi.org/10.1016/j.prostr.2019.12.025

[11] NESLÁDEK, M. et. al. (2018) Thermo-Mechanical Fatigue Analysis of a Steam Turbine Shaft. Acta Polytechnica CTU Proceedings 20. 2018. pp. 56-64.

[12] NIESLONY A., MACHA E. (2007). Spectral Method in Multiaxial Random Fatigue. Opole: Springer, 2007. pp. 152.

[13] NIESLONY, A. (2016). A critical analysis of the Mises stress criterion used in frequency domain fatigue life prediction. Frattura ed Integrità Strutturale. Vol. 10, no. 38. 2016. pp. 177-183.
[14] NIESLONY, A. et al. (2012). Fatigue life prediction for broad-band multiaxial loading with various PSD curve shapes. International Journal of Fatigue. Vol.44. 2012. pp. 74-88. doi: https://doi.org/10.1016/j.ijfatigue.2012.05.014

[15] NIESŁONY, A. et al. (2014). Multiaxial fatigue behaviour of AA6068 and AA2017A aluminium alloys under in-phase bending with torsion loading condition. In Materialwissenschaft und Werkstofftechnik. 2014. Vol. 45, no. 10, pp. 947-952.

[16] NIESLONY, A., MACHA, E. (2007). Spectral method in multiaxial random fatigue (Vol. 33). Springer Science \& Business Media. 2007

[17] PAPUGA, J. - FOJTÍK, F. (2017). Multiaxial fatigue strength of common structural steel and the response of some estimation methods. In International Journal of Fatigue. 2017. Vol. 104, pp. 27-42.

[18] PAPUGA, J. (2011). A survey on evaluating the fatigue limit under multiaxial loading. In International Journal of Fatigue. 2011. Vol. 33, no. 2, pp. 153-165.

[19] PAPUGA, J. Quest for Fatigue Limit Prediction Under Multiaxial Loading. In Procedia Engineering . 2013. Vol. 66, pp. 587-597.

[20] TREBUŇA F., JURICA V., ŠIMČÁK F. (2002). Elasticity and strength II. Košice: Publishers of Michal Vaško, 2002. pp. 318. ISBN 807165-364-0. [Slovak]

[21] TREBUŇA F., PÁSTOR M. (2017). Fatigue test machine for bending and torsion - Schenck PWS 0007. Košice: TU Košice, 2017. pp. 35. [Slovak] 